\title{
Comparação entre o Perfil dos Evadidos e dos Egressos de um Curso de Tecnologia
}

\author{
Tamires Rocha ${ }^{1}$, Elaine Santos ${ }^{1}$, Vilson Brasileiro Júnior ${ }^{1}$, Cleyton Souza ${ }^{1}$ \\ ${ }^{1}$ Instituto Federal de Educação, Ciência e Tecnologia da Paraíba (IFPB) \\ PB-264, s/n, Vila Santa Maria - Monteiro - PB - Brasil. \\ \{tamires.siqueira, elaine.santos\} @academico.ifpb.edu.br, \\ \{vilson.brasileiro, cleyton.souza\}@ifpb.edu.br
}

\begin{abstract}
In the last decade, there has been an expansion of policies to encourage students to enter higher education. However, the same concern was not observed with regard to retaining these students in these systems. The area of Information Technology is one of those that most needs the workforce. To meet the demands of the market, it is necessary to train qualified professionals. However, their courses present a higher dropout rate. Thus, aiming to incentive the permanence of students, the present study intends to draw a comparison between the characteristics of students who gave up from a course in this area and the students who were successful and completed the same course. The results demonstrate the social and professional transformation that alumni have passed. In addition, we outline possible reasons that may have contributed to the student's evasion.
\end{abstract}

Resumo. Na última década, houve uma expansão das políticas de incentivo ao ingresso dos estudantes na educação superior. Entretanto, essa mesma preocupação não foi observada no que diz respeito a favorecer a permanência desses alunos nesses sistemas. A área de Tecnologia da Informação é uma das que mais necessita de mão de obra e para atender as demandas do mercado é necessária a formação de profissionais qualificados. Contudo, essa mesma área apresenta uma taxa elevada de evasão. Dessa forma, objetivando incentivar a permanência de estudantes, o presente estudo pretende traçar uma comparação entre as características de alunos que evadiram de um curso dessa área e os alunos que lograram êxito e concluíram o mesmo curso. Os resultados demonstram a transformação social e profissional pela qual os egressos passaram, bem como delineia possiveis razões que podem ter contribuído na evasão dos ex-alunos.

\section{Introdução}

Nas últimas décadas, houve uma grande expansão de políticas públicas com a finalidade de promover o ingresso de alunos no nível superior, tanto em IES públicas quanto privadas (BARROS, 2015). Entretanto, as políticas efetivas de favorecimento a permanência desses alunos não têm sido suficientes para mantê-los nas instituições, até a conclusão do curso. Muitos desses alunos são desligados, jubilados ou simplesmente abandonam o curso que optaram. 
De acordo por Adachi (2009), a evasão é um fenômeno bastante conhecido e estudado, pelo menos, no âmbito dos sistemas educacionais brasileiros. Isso porque muitos estudos têm sido realizados, ao longo dos anos, a fim de caracterizá-la e levantar os fatores que contribuem tanto para a sua perpetuação, ao longo do tempo, quanto ações que poderiam ser adotadas para mitigar sua ocorrência. Em adição, o conhecimento que se tem é pouco compartilhado entre os gestores das IES, o que faz com que informações se percam ou fiquem isoladas e, assim, dificultando ações de combate efetivo a evasão (HOFFMANN, 2016). As informações acerca da evasão são de fundamental importância para a gestão universitária das IES.

A área de Tecnologia da Informação (TI) consiste em uma das áreas que mais necessitam de mão de obra qualificada (CARDOSO e DAVID, 2016). Estima-se que, até 2022, haverá uma demanda de 1,7 milhões de profissionais, e um déficit aproximado de 408 mil, correspondendo a 24.4\% de vagas ficando ociosas (SOFTEX, 2013). Ramos e Joia (2014) relacionam a escassez de profissionais na área de TI com o próprio aumento na demanda das empresas por esse setor, uma vez que todas as organizações estão investindo em serviços de tecnologia para se sobressair diante do mercado mais competitivo. Entretanto, historicamente, os cursos de TI possuem uma alta taxa de evasão, em comparação com demais cursos no mesmo nível (Portal G1, 2012).

Nesse sentido, objetivando incentivar a permanência de estudantes na área de TI, o presente estudo pretende traçar uma comparação entre as características de alunos que evadiram de um curso dessa área e os alunos que lograram êxito e concluíram o mesmo curso. Acredita-se que se os estudantes soubessem o impacto social e econômico que a formação nessa área pode causar em suas vidas, eles refletiriam mais, antes de desistir de um curso. Além da comparação, os resultados também incluem possíveis razões que podem ter contribuído na evasão dos ex-alunos. Essa pesquisa foi desenvolvida com exalunos (evadidos e egressos) do Curso Superior de Tecnologia (CST) em Análise e Desenvolvimento de Sistemas (ADS) do Instituto Federal de Educação, Ciência e Tecnologia da Paraíba (IFPB) - Campus Monteiro ${ }^{1}$. Esse é o único curso superior, na área de tecnologia, da região do Cariri Paraibano e, o Campus em questão, está localizado próximo à divisa do estado de Pernambuco.

\section{Fundamentação Teórica}

A evasão no ensino superior é tema recorrente em trabalhos acadêmicos no mundo todo. Mercuri e Fior (2017) afirmam que a evasão é um fenômeno geralmente multifatorial, o qual incorpora fatores de ordem temporal, pessoal e institucional. Essa mesma visão já era apontada em (TINTO, 1975) e em sua série de trabalhos acerca da evasão.

Outros autores, como é o caso de Adachi (2009), avaliam que os fatores socioculturais e econômicos são os que desempenham papéis importantes na evasão escolar. Na prática, essa seria mais uma forma de classificar as motivações do aluno para abandonar o curso. Além disso, a autora destaca que os estudos sobre evasão são de grande importância para a gestão universitária, pois são capazes de municiar os gestores com subsídios que podem guiar suas ações.

\footnotetext{
${ }^{1}$ https://estudante.ifpb.edu.br/cursos/13
} 
A evasão nos cursos relacionados à área de exatas é reconhecidamente maior, especialmente quando analisados os cursos de Computação (e suas diversas variações). Em um levantamento realizado pela UFPE, se identificou que os cursos da área de exatas possuem uma taxa de evasão superior aos demais cursos ofertados pela referida instituição (UFPE, 2016). Moraes e Pombeiro (2015) afirmam que nos cursos de computação a evasão vem crescendo continuamente.

Diversos estudos se propõem a identificar quais os fatores que influenciam na evasão discente. Para parametrizar o fenômeno, eles procuram delinear comparações entre o perfil daqueles propensos a evadir e dos estudantes com maiores chances de concluir seus cursos. Um desses trabalhos é o de Neres (2015). Nele, o autor buscou avaliar o perfil e a situação atual tanto de egressos quanto de evadidos da UNB -

Campus Planaltina. Seus resultados demonstraram que as dificuldades econômicas contribuíram de forma enfática para a evasão desses estudantes. Além disso, demonstrou a baixa empregabilidade e uma baixa adesão dos egressos a sua área de formação. Por outro lado, um estudo realizado por Moraes e Pombeiro (2015), com estudantes evadidos e egressos de diferentes cursos de Computação da cidade de Curitiba, identificou que um dos principais motivos para a evasão é a falta de conhecimento prévio acerca do que é trabalhado no curso.

No que se refere aos impactos das políticas de assistência estudantil, tem-se verificado resultados satisfatórios no que diz respeito aos resultados alcançados, em termos de incremento no número de egressos e de fomento à ascensão social, como apurado por Vargas (2010), quando o autor estudou a influência dessas políticas no âmbito da UFMG.

Diante da importância que tanto os egressos quanto os evadidos tem, em termos de informações, a respeito da qualidade do curso e sobre suas experiências com o mesmo, o presente estudo se propôs a contatar esses ex-alunos a fim de estabelecer paralelos entre os dois grupos, bem como esclarecer quais fatores mais contribuíram para evasão no curso.

\section{Metodologia}

O presente estudo pode ser classificado como uma pesquisa do tipo descritiva, de temporalidade transversal e de natureza quanti-qualitativa. De acordo com Appolinário (2009), a pesquisa do tipo descritiva visa caracterizar um determinado fato ou fenômeno de modo natural, sem qualquer modificação intencional do local analisado pelo pesquisador. Por sua vez, os trabalhos de temporalidade transversal buscam observar fatos ou fenômenos em um único momento de tempo, sem que exista seguimento do comportamento da amostra em outras oportunidades.

O universo deste trabalho é constituído por aproximadamente 279 de indivíduos evadidos do CST em ADS do Campus Monteiro e de 21 alunos egressos do CST em ADS, considerando um recorte temporal equivalente ao período retroativo de seis anos. Para ambos os grupos, buscando adequar a proposta do estudo aos objetivos, optou-se pela realização de duas coletas de dados: a primeira consiste em uma análise documental das fichas de matrícula e de dados oriundos do Sistema Unificado de Administração Pública do IFPB (SUAP); a segunda consistiu na aplicação de 
questionários eletrônicos individuais aos egressos e aos evadidos com questionamentos semelhantes.

Para a aplicação dos questionários, os indivíduos foram convidados por e-mail a participar do estudo. No e-mail, era apresentada ao possível participante a proposta do estudo e a importância da sua participação para melhoria do curso. Por fim, o candidato era convidado a participar acessando um link disponibilizado no corpo do e-mail.

No levantamento de dados junto ao controle acadêmico, foram identificados 279 alunos evadidos, dentro os quais 184 possuíam um e-mail de contato cadastrado em seu registro. Entretanto, apenas 157 desses alunos possuíam um endereço de e-mail válido, dos quais $31,21 \%$ aceitaram participar do estudo. No que se refere aos egressos, foram enviados e-mails aos 21 indivíduos, entretanto, obteve-se a participação efetiva de 19 $(90 \%)$ deles.

O formulário destinado aos evadidos possuía a finalidade de coletar dados acerca da evasão desses discentes que abandonaram o curso, enquanto que o documento destinado aos egressos objetivava obter dados para traçar o perfil profissional e socioeconômico dos alunos que obtiveram êxito na graduação. Entretanto, ambos os instrumentos de coleta de dados também possuíam questionamentos similares, a fim de possibilitar a identificação de paralelos entre os egressos e evadidos.

O formulário eletrônico dos egressos era dividido em oito seções para facilitar a organização do documento, ao passo que o dos evadidos possuía sete. Em ambos, na primeira seção do formulário, o indivíduo era convidado a participar, devendo concordar, de forma eletrônica, com o Termo de Consentimento Livre Esclarecido (TCLE). Além disso, a depender das respostas do participante, havia sessões condicionadas a receber um número menor de respostas, uma vez que havia interdependência entre algumas sessões (i.e., a visualização de algumas partes do questionário estava condicionada a uma resposta específica em uma seção anterior). Ao final do TCLE, caso o ex-aluno não quisesse participar do estudo, o mesmo era direcionado ao final do formulário e sua opção era registrada. Apesar de ter-se obtido uma amostra razoável, conjectura-se que a extensão do instrumento de coleta de dados possa ter desestimulado alguns egressos a participarem do estudo. Os formulários recebidos passaram por verificação, a fim de garantir que um mesmo participante não participasse duas vezes do estudo (em caso de ocorrência, definiu-se que apenas a última resposta seria considerada para fins de análise). Todas as respostas, de ambos os formulários, podem ser obtidas por solicitação aos autores desse estudo.

Como mencionado anteriormente, desde sua criação até o primeiro semestre do ano de 2018, o CST de ADS formou vinte e um alunos. Em contrapartida, dados do Controle Acadêmico da instituição indicam que duzentos e setenta e nove alunos evadiram do curso. Em outras palavras, o número de alunos que desistem do curso de ADS é aproximadamente 14 vezes maior que o número de egressos. Essa estatística é alarmante, mas é uma característica marcante na maioria dos cursos de tecnologia da área de Computação, conforme detalhado previamente. 


\section{Resultados}

Os questionamentos presentes nos dois estudos indagavam as duas amostras sobre: quais foram os motivadores para sua opção pelo curso; em que turnos costumavam frequentar o campus; se eles eram responsáveis pelo sustento da família, enquanto alunos do curso; quais meios de transporte eram utilizados para fazer o trajeto entre a sua residência e a instituição; se eram beneficiários de programas ou políticas de assistência estudantil; a sua percepção sobre o nível de dificuldade do curso; assim como, qual sua renda mensal atual. Os pontos onde houve diferenciação evidente serão enumerados a seguir.

O Quadro 1 detalha quais fatores mais influenciaram na opção do aluno pelo curso de ADS (os respondentes podiam escolher mais de uma razão).

Quadro 1: 0 que motivou a sua inserção no CST em ADS

\begin{tabular}{|l|c|c|}
\hline \multicolumn{1}{|c|}{ MOTIVO } & EVADIDOS & EGRESSOS \\
\hline Afinidade com a área & $77,6 \%$ & $79 \%$ \\
\hline Boa inserção no mercado de trabalho & $34,7 \%$ & $58 \%$ \\
\hline Expectativa de boa remuneração quando formado & $22,4 \%$ & $53 \%$ \\
\hline Proximidade com a cidade de origem & $30,6 \%$ & $79 \%$ \\
\hline Baixa nota de ingresso & $4,1 \%$ & $5 \%$ \\
\hline Afinidade com o curso & $4,1 \%$ & $5 \%$ \\
\hline
\end{tabular}

Quanto aos resultados descritos no Quadro 1, verifica-se que a "afinidade com a área do curso" foi a motivação mais relevante tanto para os egressos quanto para os evadidos. Outro fator, que influenciou principalmente os egressos, foi a "proximidade com a cidade de origem". Acredita-se que essa razão seja de fato bastante relevante na opção dos alunos que residem em áreas distantes de grandes centros, onde a oferta de cursos superiores é pouco variada.

Outro ponto de diferenciação nas respostas, diz respeito aos turnos em que os exalunos frequentavam o campus. Destaca-se que o curso de ADS é um curso noturno. Mas, como pode ser observado na Figura 1, existe uma discrepância significativa, ao comparar as respostas dos dois grupos. 


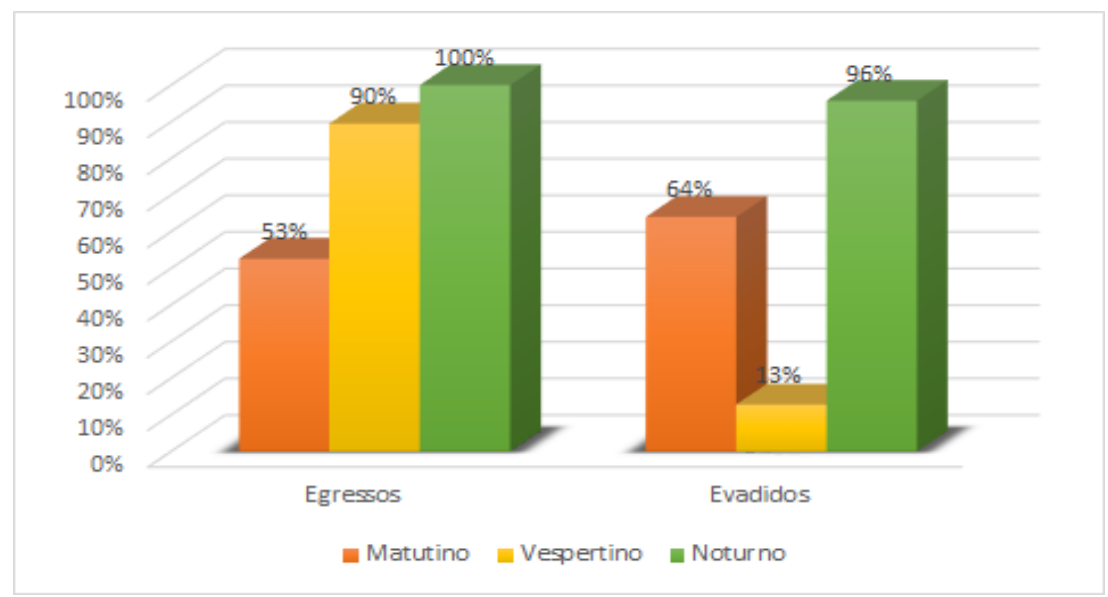

Figura 1: Turnos em que os egressos e evadidos costumavam frequentar 0 campus.

Os resultados observados na Figura 1 demonstram que a maioria dos egressos frequentava o Campus em diversos períodos do dia, mesmo as aulas sendo apenas a noite. Quase 90\% dos egressos permaneciam no Campus em, pelo menos, mais de um turno, enquanto que apenas $12 \%$ dos evadidos tinham o mesmo hábito. Isso destaca a importância dessas horas extras no desempenho e na formação dos alunos, pois os permite se envolver em atividades de pesquisa, extensão e monitoria, com muito mais facilidade.

Buscou-se avaliar a percepção dos ex-alunos quanto ao nível de dificuldade do curso ADS. As respostas encontram-se sumarizadas na Figura 2.

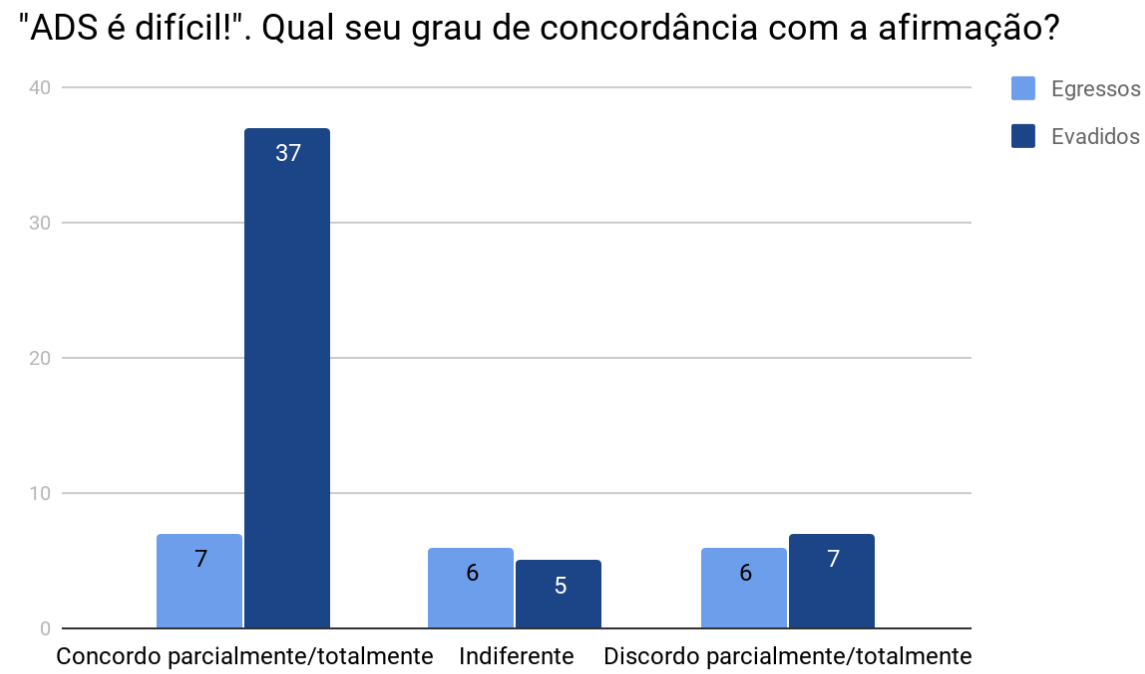

Figura 2: Percepção dos ex-alunos acerca do nível de dificuldade do curso.

No que se refere às respostas apresentadas na Figura 2, nota-se que existe uma expressiva discrepância no nível de concordância creditado por evadidos e egressos. No geral, a maioria dos evadidos concorda que o curso é difícil, enquanto que as respostas encontram-se melhor distribuídas no grupo dos egressos. Outro dado interessante diz 
respeito a quantidade de períodos cursados até o afastamento da instituição. Entre os evadidos, 49,2\% afirmaram ter cursado apenas um período, 18,4\% cursaram dois semestres e 38,8\% cursaram entre três e seis semestres. Desse modo, pode-se verificar uma forte concentração da evasão discente nos primeiros semestres do curso e a sua importância para o sucesso do curso do aluno. Nota-se uma consonância dos resultados obtidos, em relação ao que foi apurado por outros autores, tais como Silva Filho et al. (2007); Adachi (2009); Saccaro, França e Jacinto (2016), no sentido de que a evasão nos casos estudados concentrou-se nos primeiros semestres do curso. Por outro lado, entre os egressos, verificou-se que o tempo médio de permanência na instituição é de oito semestres, mesmo o curso tendo duração mínima de sete, o que revela a necessidade de grande parte dos egressos por um período adicional para concluir o curso. Além disso, cabe destacar que $38,8 \%$ dos evadidos afirmaram que possuíam dificuldades em disciplinas específicas do curso, a maioria em disciplinas relacionadas com programação, sendo esse a segunda justificativa mais recorrente para a desistência dos alunos.

Também foi questionado se os ex-alunos, na época da graduação, eram os responsáveis pelo sustento familiar. Quanto a isso, 66,7\% dos evadidos afirmaram não possuir tal responsabilidade e 33,3\% responderam que sim. No grupo dos egressos, esse percentual é um pouco menor, sendo apenas $21 \%$ aqueles responsáveis pelo sustento da família. Acredita-se que esse resultado seja interessante porque revela que, não necessariamente, a maioria dos evadidos é provedora do lar. Percebe-se que, mesmo com tamanho de amostras diferentes, proporcionalmente não há diferenças significativas. De toda forma, vale ressaltar que a maioria dos evadidos justifica a desistência do curso, justamente, pela dificuldade em conciliar o seu trabalho com as atividades estudantis, sendo esse, talvez, o segredo para o sucesso no curso.

Quanto ao meio de transporte utilizado para se locomover, 55\% dos evadidos informaram se deslocar ao Campus usando ônibus ou carro fretado, 15\% faziam o trajeto casa-instituição a pé, $15 \%$ utilizavam moto própria e outros $15 \%$ optavam por moto-táxi. Por outro lado, $42,8 \%$ dos egressos do curso escolheram moto própria como meio mais utilizado para se deslocarem de suas casas para o Campus e vice versa, $26,3 \%$ usava ônibus ou carro fretado e $21 \%$ fazia o trajeto a pé. Quando essa informação é confrontada junto com o tempo que esse deslocamento levava, percebe-se que todos os egressos levavam menos de uma hora para chegar ao Campus (sendo que metade deles levava menos de 15 minutos). Entretanto, 40\% dos evadidos levavam menos de uma hora e $25 \%$ levavam mais de uma hora. Assim, acredita-se que a dificuldade de acesso à instituição somada à duração do translado podem contribuir na decisão de desistência dos alunos. Destaca-se também que quase $60 \%$ dos alunos que evadiram informara enfrentar dificuldades de transporte, durante o período que estavam no curso, dentre os quais mais da metade (55\%) acreditava, antes de ingressar, que esse fato poderia atrapalhar seu desempenho.

Quando questionados se os programas de incentivo à permanência do aluno no curso (os auxílios estudantis), de fato, influenciam na continuidade da graduação, a maioria dos egressos $(52,6 \%)$ afirmou que sim. Contudo, o resultado desse questionamento, quando feito aos evadidos, mostrou que, diferente dos egressos, a maior parte dos alunos que evadiram do curso (62,5\%) não eram beneficiados com nenhum tipo de programa ou política de assistência estudantil e apenas $37,5 \%$ eram 
beneficiários. Como demonstrado por Neres (2015), as políticas de assistência estudantil, de fato, mitigam o fenômeno da evasão, uma vez que os alunos com dificuldades financeiras, sem esse suporte, tendem a abandonar o curso.

Quanto à ocupação atual, verificou-se que, no grupo dos egressos, 52,6\% estão trabalhando na área; 26,3\% não apenas trabalham na área como também estudam; 5,3\% apenas estudam na área; e 15,8\% encontram-se atuando em outra área de formação. $\mathrm{O}$ que revela uma adesão de $85 \%$ dos egressos à sua área de formação. Entre os evadidos, $32,7 \%$ afirmaram estar cursando outro curso superior; $30,6 \%$ estão apenas trabalhando; $14,3 \%$ seguem estudando para enriquecer o currículo (pós-graduação, especialização, etc.); $12,2 \%$ estão buscando emprego; e 10,2\% afirmaram que estão fazendo se preparando para concursos públicos. Esses resultados demonstram que mais da metade dos alunos que evadiram estão fora do sistema de ensino. Para o MEC (1997), a evasão de sistema do ensino ocorre quando os alunos se dedicam a outras atividades e não seguem os seus estudos. Conforme pode ser observado nas respostas, no CST em ADS, uma parcela expressiva dos alunos evadidos encontra-se afastada do ensino superior para se dedicar a trabalho ou a busca por emprego ou para se dedicar a concursos públicos.

Por fim questionou-se sobre a renda atual desses dois grupos, 50,7\% dos egressos possuem renda de até três salários mínimos, que na época da coleta de dados (2018) correspondia a $\mathrm{R} \$ 2862,00$, enquanto que $73,5 \%$ dos evadidos recebem até um salário mínimo $(\mathrm{R} \$ 954,00)$. Os resultados mostram que quem terminou o curso possui uma renda em média três vezes maior que os alunos que desistiram do curso, demonstrando que a conclusão do curso de ADS possa vir a ser um componente fundamental para a ascensão de renda dos seus estudantes. Nesse sentido, destaca-se que $78,9 \%$ dos egressos concordam que sua qualidade de vida melhorou, após a conclusão do curso.

\section{Conclusão e Trabalhos Futuros}

Nesse estudo, procurou-se traçar uma comparação entre as características destoantes dos alunos evadidos e dos egressos do CST em ADS, oferecido pelo IFPB - Campus Monteiro. Percebeu-se que a expressiva maioria desses indivíduos ingressa no curso com interesses e aptidões semelhantes, entretanto os evadidos frustram-se, ainda nos primeiros semestres. Por isso, parte considerável acaba por evadir, estimulada, principalmente, por dificuldades nas disciplinas consideradas como base do curso (programação). Em adição, ressalta-se a necessidade de adoção de medidas que viabilizem maior flexibilidade curricular e ao acesso aos auxílios estudantis, principalmente para os indivíduos responsáveis pelo sustento da família e que necessitam trabalhar, visto que, no contexto estudado, a sua dedicação ao curso é prejudicada.

De toda forma, quanto à política de assistência estudantil, o presente estudo comprovou a importância desse tipo de incentivo, visto que o recebimento de auxílio reduz as chances dos alunos evadirem do curso. Além disso, foi possível afirmar o papel da instituição como agente modificador social na vida desses estudantes egressos, uma vez que a renda dos estudantes que obtiveram êxito é relativamente maior que dos 
estudantes que evadiram. Além dos egressos terem destacado uma melhora na qualidade de vida, após o curso.

Os resultados obtidos no presente estudo apontam para a necessidade de identificação precoce dos alunos com dificuldades nas disciplinas ligadas à programação e da criação de ações voltadas tanto para os alunos com dificuldades bem como, para os estudantes que trabalham. Além disso, vislumbra-se a utilização dos dados coletados para a construção de um modelo preditivo que leve em consideração as características dos egressos e dos evadidos, a fim de detectar, com antecedência, os indivíduos que possuem características de um aluno propenso a evadir ou não.

\section{Agradecimentos}

Gostaríamos de agradecer o apoio do IFPB - Campus Monteiro no desenvolvimento dessa pesquisa, bem como dos ex-alunos que participaram, respondendo o questionário.

\section{Referências}

Adachi, A. (2009). "Evasão e evadidos nos cursos de graduação da Universidade Federal de Minas Gerais", Dissertação de Mestrado. Faculdade de Educação, UFMG. Disponível em: <http://www.bibliotecadigital.ufmg.br/dspace/handle/1843/HJPB7UPMBA>. Acesso em: 11 jan. 2019.

Appolinário, F. (2009) "Dicionário de metodologia científica: um guia para a produção do conhecimento científico". São Paulo, Atlas.

Barros, A. (2015). "Expansão da Educação Superior no Brasil: Limites e Possibilidades". Campinas - SP: Educação e Sociedade, v.36, n. 131, p 361-390. Disponível em: <http://www.scielo.br/pdf/es/v36n131/1678-4626-es-36-13100361.pdf $>$. Acesso em: 07 de janeiro de 2019.

MEC. (1997). "Diplomação, retenção e Evasão nos cursos de graduação em instituições de Ensino Superior Públicas". Comissão Especial de Estudos sobre a Evasão nas Universidades Públicas Brasileiras. Disponível em: $<$ http://www.dominiopublico.gov.br/download/texto/me001613.pdf $>$. Acesso em: 29 de janeiro de 2019.

Cardoso, E. e David, T. (2016) "A falta de profissionais de tecnologia de informação no mercado de trabalho: A transformação da capacidade profissional pelos deveres: mérito individual". In: Congresso Internacional uma nova pedagogia para a sociedade futura: protagonismo responsável, p. 697-700.

Hoffmann, I. (2016) "Metodologia para Identificação dos Fatores Estratégicos para o Acompanhamento Sistemático da Evasão em Cursos De Graduação". Dissertação (Mestrado em Engenharia de Produção) - Universidade Federal de Santa Maria, Santa Maria - RS. Disponível em: <https://repositorio.ufsm.br/handle/1/8385>. Acesso em: 09 de janeiro de 2019.

Mercuri, E. e Fior, C. (2012) "Análise dos fatores preditivos da evasão em uma universidade confessional". In: CLABES, Disponível em: $<$ http://revistas.utp.ac.pa/index.php/clabes/article/view/872>. Acesso em: 1 de fevereiro de 2019. 
Moraes, M. e Pombeiro, O. (2015) "Evasão nos cursos de graduação em Computação de Curitiba". Anais do Evento de Iniciação Científica da UNIBRASIL. Disponível em: $<\mathrm{http}$ //portaldeperiodicos.unibrasil.com.br/index.php/anaisevinci/article/view/1081> . Acesso em: 31 de fevereiro de 2019.

Neres, I. (2015) "Comparação do perfil e da situação entre o aluno evadido e o egresso da faculdade UnB / Planaltina - FUP”. Dissertação de Mestrado em Políticas Públicas - Faculdade UnB de Planaltina, Universidade de Brasília. Disponível em: $<$ http://www.gestaopublica.unb.br/images/Resumos2015/2015_IvonaldoVieiraNeres. pdf $>$. Acesso em: 31 de fevereiro de 2019.

Portal G1. "Índice de evasão de alunos é maior na área de tecnologia da informação". Disponível em: <http://g1.globo.com/sp/sao-carlos-regiao/noticia/2012/09/indice-deevasao-de-alunos-e-maior-na-area-de-tecnologia-da-informacao.html $>$. Acesso em: 1 de abril 2019.

Saccaro, A.; França, M. e Jacinto, P. (2016) "Retenção e evasão no Ensino Superior Brasileiro: uma análise dos efeitos da bolsa permanência do PNAES". In: ENCONTRO NACIONAL DE ECONOMIA, 44, 2016, Niterói. Disponível em: $<$ https://www.anpec.org.br/encontro/2016/submissao/files_I/i12707be73e05304f27eb 9f18ae5d235c9d.pdf $>$. Acesso em: 28 de janeiro de 2019.

Silva Filho, R.; Montejunas, P.; Hipólito, O. e Lobo, M. (2007) “A evasão no ensino superior brasileiro". Cadernos de Pesquisa, São Paulo, v. 37, n. 132, p. 641-659. Disponível em: <http://www.institutolobo.org.br/imagens/pdf/artigos/art_045.pdf>. Acesso em: 01 de janeiro de 2019.

SOFTEX (2013). "Mercado de trabalho e formação de mão de obra em TI Relatório Técnico". In: Cadernos Temáticos do Observatório.

Tinto, V. (1975). "Dropout from Higher Education: A Theoretical Synthesis of Recent Research”. Washington, Review of Educational Research, v. 45, n. 1, p. 89-125.

UFPE (2016) "Causas da evasão de alunos nos cursos de graduação presencial da UFPE”. Pró-Reitoria de Planejamento, Orçamento e Finanças. Disponível em: $<$ https://www.ufpe.br/documents/38954/371376/r_evaso_16.pdf/53642e52-41fb4b43-b098-98db6a470176>. Acesso em: 01 de fevereiro de 2019.

Vargas, M. (2011) "Ensino superior, assistência estudantil e mercado de trabalho: um estudo com egressos da UFMG". Avaliação (Campinas), Sorocaba, v. 16, n. 1, p. 149-163. Disponível em: $<$ http://www.scielo.br/scielo.php?script=sci_arttext\&pid=S1414$40772011000100008 \& \operatorname{lng}=$ en\&nrm=iso $>$. Acesso em: 01 de fevereiro de 2019. 